\title{
Wall Heat Flux Measurements for a Kerosene-Fueled Supersonic Combustor
}

\author{
Di Cheng ${ }^{1}$; Jing Wang ${ }^{2}$; Yang $\mathrm{Lu}^{3}$; Long Li ${ }^{4}$; Wei Yao ${ }^{5}$; and Xuejun Fan ${ }^{6}$
}

\begin{abstract}
Wall heat flux distributions under different configurations for a kerosene-fueled supersonic combustor were experimentally studied. The influences of combustion, global fuel equivalence ratio, mass flow rate, total temperature, and inlet Mach number on the wall heat flux of the kerosene-fueled supersonic combustor were systematically presented and analyzed for the first time. Methods to calibrate and validate the in-house-developed heat flux sensors are also presented. The revealed trends would be useful to guide the design of thermal management systems for kerosene-fueled scramjets. DOI: 10.1061/(ASCE)AS.1943-5525.0001076. ( 2019 American Society of Civil Engineers.
\end{abstract}

Author keywords: Heat flux measurement; Kerosene; Supersonic combustion; Scramjet; Heat flux sensor.

\section{Introduction}

Wall heat flux is a critical design parameter for the cooling facilities of supersonic combustors because it quantifies the thermal load relative to the wall material limit. The wall heat flux after applying the cooling facility characterizes the overall performance of the thermal management system. However, heat flux measurements for supersonic combustors are still rare in the literature. One important reason is that the wall heat flux of supersonic combustors usually exceeds the measuring range of commercial heat flux sensors (Trelewicz et al. 2015). For typical hypersonic speeds with $\mathrm{Ma} \geq 5$, the total temperature of reacted gases may become much larger than $2,800 \mathrm{~K}$, and the wall heat flux can easily exceed $10.0 \mathrm{MW} / \mathrm{m}^{2}$ (Heiser and Pratt 1994). To measure the heat flux of long-duration supersonic combustors, a Gardon-type heat flux sensor with additional water cooling has been developed in a previous study by Li et al. (2012).

As an important indicator of the internal combustion, the wall heat flux distribution is significantly influenced by the

\footnotetext{
${ }^{1}$ Engineer, Research and Development Center, China Academy of Aerospace Aerodynamics, Beijing 100074, China; Postdoctoral Researcher, Dept. of Mechanical Engineering, Univ. of Connecticut, Storrs, CT 06269. Email: di.cheng@uconn.edu

${ }^{2}$ Senior Engineer, Key Laboratory of High Temperature Gas Dynamics, Institute of Mechanics, Chinese Academy of Sciences, Beijing 100190, China (corresponding author). Email: wangjing@imech.ac.cn

${ }^{3}$ Associate Professor, Key Laboratory of High Temperature Gas Dynamics, Institute of Mechanics, Chinese Academy of Sciences, Beijing 100190, China. Email: luyang@imech.ac.cn

${ }^{4}$ Professor, Key Laboratory of High Temperature Gas Dynamics, Institute of Mechanics, Chinese Academy of Sciences, Beijing 100190, China. Email: lilong@imech.ac.cn

${ }^{5}$ Associate Professor, Key Laboratory of High Temperature Gas Dynamics, Institute of Mechanics, Chinese Academy of Sciences, Beijing 100190, China; Professor, School of Engineering Science, Univ. of Chinese Academy of Sciences, Beijing 100049, China. Email: weiyao@ imech.ac.cn

${ }^{6}$ Professor, Key Laboratory of High Temperature Gas Dynamics, Institute of Mechanics, Chinese Academy of Sciences, Beijing 100190, China; Professor, School of Engineering Science, Univ. of Chinese Academy of Sciences, Beijing 100049, China. Email: xfan@imech.ac.cn

Note. This manuscript was submitted on February 1, 2019; approved on April 29, 2019; published online on July 15, 2019. Discussion period open until December 15, 2019; separate discussions must be submitted for individual papers. This paper is part of the Journal of Aerospace Engineering, (C) ASCE, ISSN 0893-1321.
}

combustor configurations. Morgan and Stalker (1986) showed that the measured values of heat flux for the examined supersonic combustor lie between the laminar and turbulent empirical values, implying that the influence of the locally based Reynolds number has not been fully understood. The influence of thermal stratification on the distribution of wall heat flux was found to be significant by Stouffer et al. (1997). Traci et al. (2002) showed that the peak wall heat flux in a direct-connect supersonic combustor increases with the global equivalence ratio to a fuel-rich condition, and then decreases with the further increase of the global equivalence ratio. Gardner et al. (2004) observed that for the hydrogen-fueled HyShot combustor, the heat flux increases with the global equivalence ratio (under the fuel-lean condition) and angle of attack. Ueda et al. (2006) investigated the influence of different fuel injection schemes, that is, sidewall, strut, and multistage injection in a hydrogenfueled combustor, and pointed out that the combination of sidewall and strut injection produces the highest thermal load on the wall. Trelewicz et al. (2015) and Kennedy et al. (2011) revealed that the overall heat flux increases with dynamic pressure and the global equivalence ratio (under fuel-lean condition) in an ethylene-fueled scramjet combustor. However, to the authors' best knowledge, there are few studies of heat flux for kerosene-fueled supersonic combustors in the literature. Because of the lower reaction rate of kerosene combustion, flame stabilization modes and corresponding wall heat flux distributions are significantly different from those fueled by hydrogen and small-molecule hydrocarbons (Yao et al. 2018a, b). Direct measurement of wall heat flux would be necessary to guide the design of cooling facilities, for example, regenerative-cooling channels, as well as to gain more understanding of the characteristics of kerosene-fueled supersonic combustion. Thus, heat flux distributions under different configurations of fuel mass flow rates, total temperatures, inlet Mach numbers, global equivalence ratios, and fuel temperatures were experimentally studied for a kerosene-fueled supersonic combustor in this study. Preliminary calibration and validation of the heat flux sensors are presented first, and the results from the ground testing of a model scramjet are reported and discussed.

\section{Experimental Approach}

\section{Supersonic Combustor}

The experimental details were presented by Cheng et al. (2016) and will be briefly introduced in the following. Fig. 1 shows the 


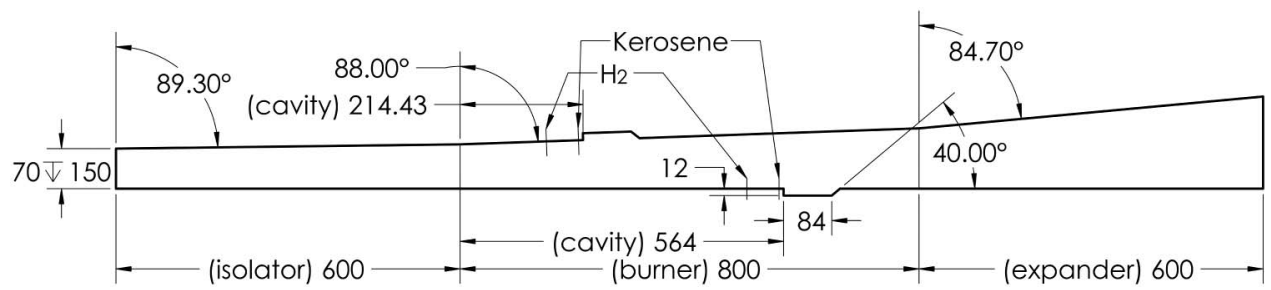

$\mathrm{H}_{2}$ injection: $4 \times \varnothing 2.56,64 \mathrm{~mm}$ ahead of cavity

Kerosene injection: $9 \times \varnothing 1.0$ for supercritical or $9 \times \phi 0.4$ for liquid, $8 \mathrm{~mm}$ ahead of cavity

Fig. 1. Schematic of the combustor assembly (length in millimeters).

schematic of a rectangular model combustor consisting of three sections: isolator, combustor, and expander. The inlet of the isolator had dimensions of $70 \times 150 \mathrm{~mm}$. The three sections were all single-side expanded with angles of $0.7^{\circ}, 2.0^{\circ}$, and $5.3^{\circ}$, respectively. The wall with side expansion is referred to as the upper wall, whereas its opposite wall is referred to as the lower wall. The combustor assembly was made of stainless steel SUS321. During the tests, the combustor was cooled by external water at freezing temperature. Square water cooling channels of $3 \times 3 \mathrm{~mm}^{2}$ were embedded into the wall, which had a total thickness of $20 \mathrm{~mm}$. The distance between two adjacent parallel cooling channels was $5 \mathrm{~mm}$. The inner wall surface was processed to have a roughness of $\varepsilon=3.2 \mu \mathrm{m}$. On the upper and lower walls, there were two dislocated cavities, which were made the same, that is, $12 \mathrm{~mm}$ in depth, $50^{\circ}$ for the aft ramp angle, and 7 for the length:depth ratio. The pilot $\mathrm{H}_{2}$ was injected at upstream locations $64 \mathrm{~mm}$ before the cavities, whereas supercritical kerosene was injected from the locations $8 \mathrm{~mm}$ ahead of the cavities. The hydrogen injectors were $2.65 \mathrm{~mm}$ in diameter, whereas the kerosene injectors were $1 \mathrm{~mm}$ in diameter. The mass flow of hydrogen was evenly distributed among four injectors, whereas the mass flow kerosene was evenly distributed among nine injectors. The kerosene was heated to $768 \pm 5 \mathrm{~K}$ to become supercritical status before the injection. During the test, the mass flow rate of kerosene was adjusted through varying the total pressure from 2.87 to $4.56 \mathrm{MPa}$. The kerosene flow was injected at sonic speed because it had been choked immediately before the injection. A two-stage injection scheme was used before the upstream and downstream cavities, and the mass flow rates of hydrogen and kerosene were evenly distributed between the upstream and downstream injectors. By using the traditional burning hydrogen with oxygen replenishment method, the total temperature of the vitiated air was raised to $700-2,200 \mathrm{~K}$, with the total pressure ranging between 0.6 and 4.0 MPa. During the tests, the maximum mass flow rate of vitiated air was $5 \mathrm{~kg} / \mathrm{s}$. The composition of the vitiated air was $\mathrm{N}_{2}$ in $59.0 \mathrm{vol} \%, \mathrm{O}_{2}$ in $20.9 \mathrm{vol} \%$, and $\mathrm{H}_{2} \mathrm{O}$ in $20.4 \mathrm{vol} \%$.

Fig. 2 shows the long-time direct-connect supersonic combustion test platform, which includes the following subsystems: supersonic combustor, nozzle, water-cooling system, fuel and air heating and supply systems, and data acquisition (DAQ) and control systems. During the tests, the model combustor was actively cooled by water whose outflow temperature was monitored to ensure a sufficient cooling effect. The data acquisition and control system was responsible for collecting the data transmitted from the pressure and heat flux sensors, which were attached to different walls of the tested supersonic combustor. The pressure transducers were attached along the centerline of the front wall, which was perpendicular to the upper and lower walls, whereas the heat flux sensors were located on the upper and the lower walls, as shown in the front view in Fig. 2. The wall temperature was not measured because it prohibitively exceeds the measuring range of current commercial aftermarket thermocouples.

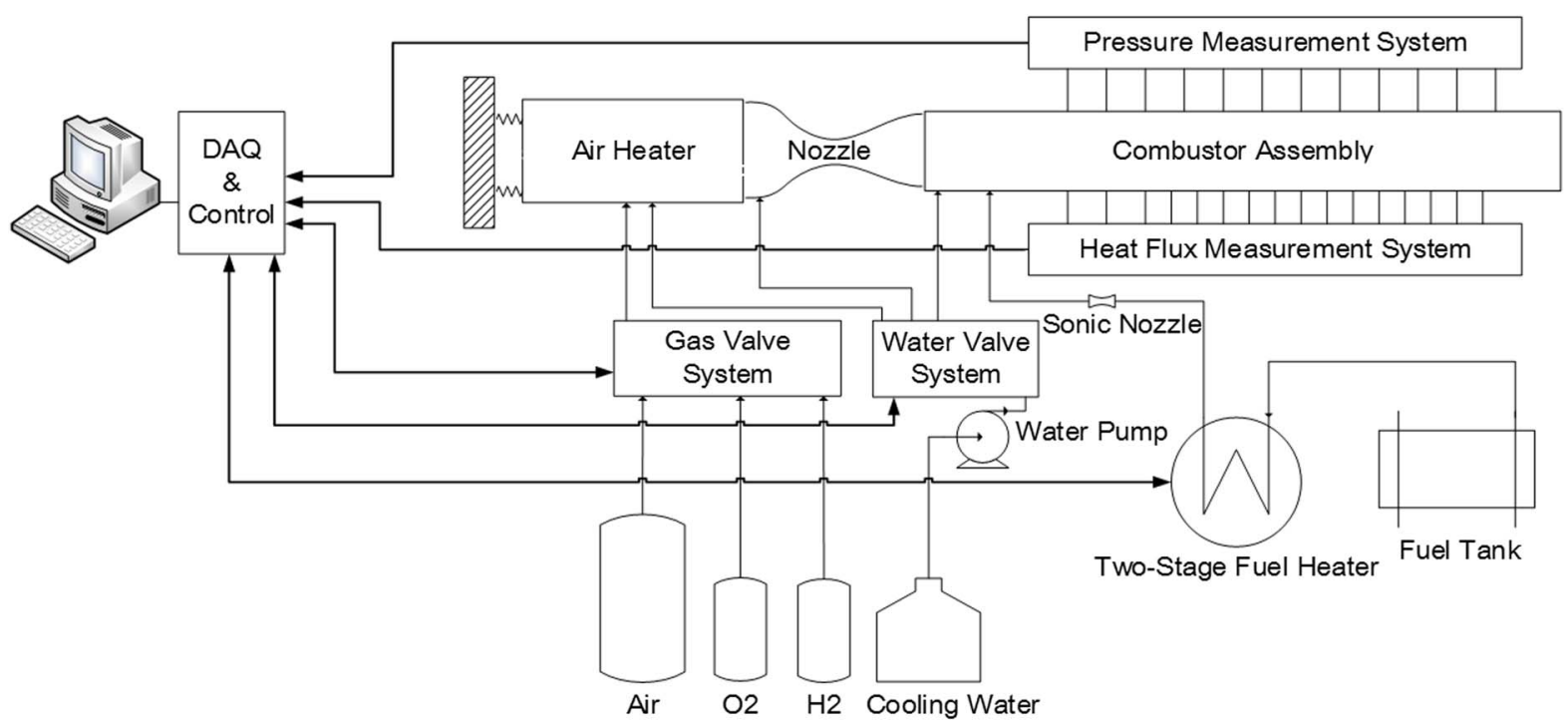

Fig. 2. Schematic diagram of the test facility. 


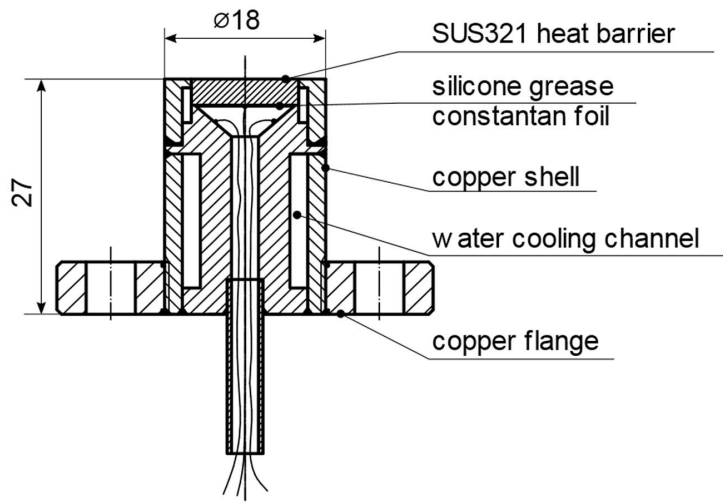

(a)

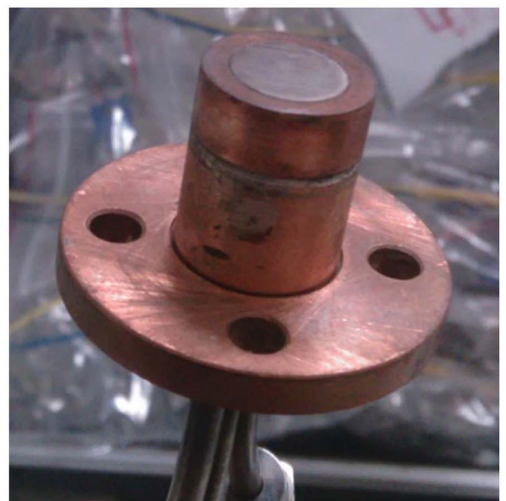

(b)

Fig. 3. (a) Schematic; and (b) photo of heat flux sensor.

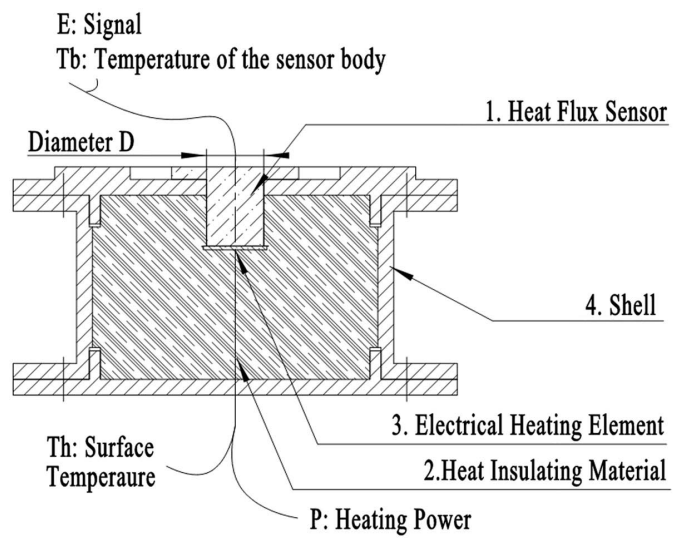

(a)

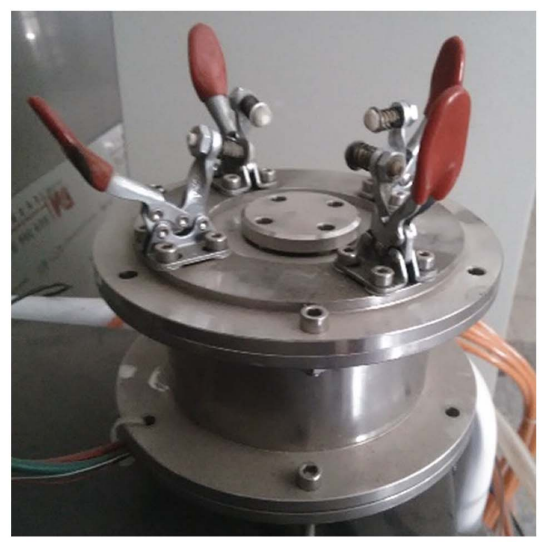

(b)

Fig. 4. (a) Schematic; and (b) photo of electrical heating method calibration device.

\section{Heat Flux Sensor}

The heat flux sensor shown in Fig. 3 was developed by Li et al. (2012) based on the principle of the Gardon gauge. Cooling water at a flow rate of $30 \mathrm{~mL} / \mathrm{s}$ was recirculated through the sensor. The sensor's header was $18 \mathrm{~mm}$ in diameter. The surface of the sensor header was polished to have the same roughness as the inner wall, that is, $\varepsilon=3.2 \mu \mathrm{m}$. The heat flux could be obtained through a prior calibration because the value was proportional to the output voltage. Twenty-four heat flux sensors were embedded into the upper, lower, and front walls along the centerlines. The sampling rate of the heat flux sensors was $10 \mathrm{~Hz}$.

\section{Calibration of the Heat Flux Sensor}

Two methods, the high-temperature black-body radiation method (HTBBRM) and electrical heating method (EHM), were used to calibrate the heat flux sensors before each test. Fig. 4 illustrates the principle of the EHM method, where through adding an insulating layer of bricks, nearly all the electric heating power is transferred through the heat flux sensor and produces the temperature difference and correspondingly the output signal $E$. The sensor sensitivities are calculated by the following linear fittings:

$$
K_{1}=\frac{4 P}{\pi D^{2} E}
$$

$$
K_{2}=\frac{T_{h}-T_{b}}{E}
$$

where $K_{1}$ and $K_{2}=$ sensitivity coefficients, respectively, for the temperature difference and the heat flux; $D=$ diameter of the sensor header; $P=$ electrical heating power; $T_{h}=$ temperature at the heater surface; and $T_{b}=$ temperature at the sensor body. The calibration based on the HTBBRM method was addressed in Li et al. (2012), where instead the heat flux is generated by black-body radiation in a graphite cavity. Compared with EHM, HTBBRM can reach a higher temperature, up to $100 \mathrm{~W} / \mathrm{cm}^{2}$, but with much higher cost. In addition, EHM can calibrate $K_{1}$ and $K_{2}$ simultaneously. The fitting results in Fig. 5(a) show that $K_{1}$ values obtained from the two methods are within an $8 \%$ difference. However, $K_{2}$ fitted in Fig. 5(b) cannot be verified because the surface temperature of the sensor header is unavailable in HTBBRM.

\section{Accuracy in Installation and Machining}

There are two types of installation errors, as schematically shown in Fig. 6. The mismatch between the flanges of two adjacent sections [as shown in Fig. 6(a)] is usually smaller than $1 \mathrm{~mm}$, whereas the largest installation error usually occurring between the isolator and the nozzle is $2 \mathrm{~mm}$. This explains the slight asymmetry of the profiles of pressure and heat flux at the first measuring location. 

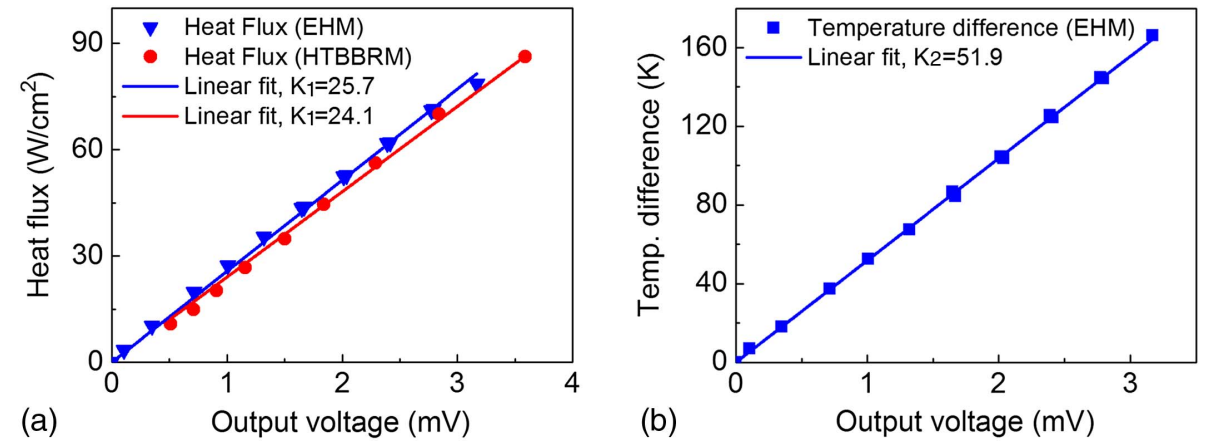

Fig. 5. Calibration data of heat flux sensor for (a) $K_{1}$; and (b) $K_{2}$.

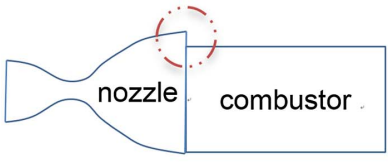

(a)

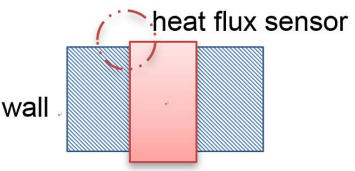

(b)
Fig. 6. Misalignments of (a) flanges; and (b) sensor heads.

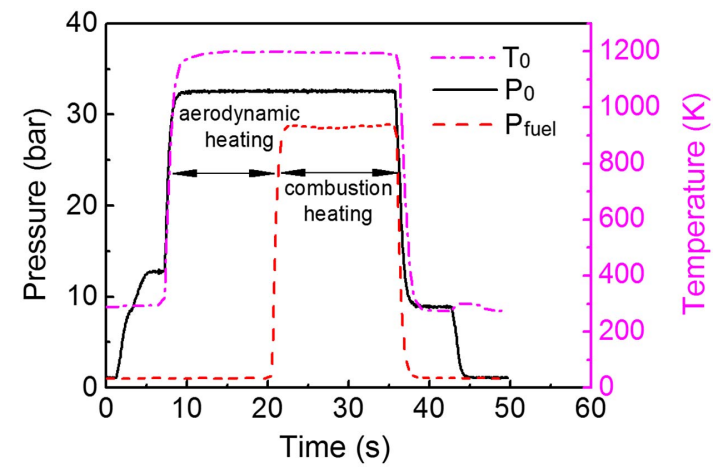

Fig. 7. Time variations of pressure and temperature during the test.

The heads of the heat flux sensors can have a small gap within $0.1 \mathrm{~mm}$, as shown in Fig. 6(b). The measurement errors caused by the previous installation and machining errors are considered small enough to cause little influence on the general trends in the following parameter analysis.

\section{Experiment Procedure}

According to the time sequence in Fig. 7, the data acquisition has a margin of $10 \mathrm{~s}$ before and after each test. The supply of vitiated air lasts from 3 to $35 \mathrm{~s}$, and the kerosene injection is injected $2 \mathrm{~s}$ after the injection of pilot hydrogen and lasts from 20 to $35 \mathrm{~s}$. The durations for aerodynamic and combustion heating are both $15 \mathrm{~s}$.

\section{Data Processing}

The configuration parameters of different tests are listed in Table 1, which includes the mass flow rate $q_{m}$, total temperature $T_{0}$, total pressure $P_{0}$ (which depends on $q_{m}$ and $T_{0}$ ), equivalence ratio of pilot hydrogen $\Phi_{H 2}$, equivalence ratio of kerosene $\Phi_{k}$, and inlet
Table 1. Summary of test cases

\begin{tabular}{lccccccc}
\hline $\begin{array}{l}\text { Test } \\
\text { number }\end{array}$ & $\mathrm{Ma}$ & $\begin{array}{c}T_{0} \\
(\mathrm{~K})\end{array}$ & $\begin{array}{c}P_{0} \\
(\mathrm{bar})\end{array}$ & $\begin{array}{c}\dot{\mathrm{m}}_{\text {air }} \\
(\mathrm{g} / \mathrm{s})\end{array}$ & $\Phi_{k}$ & $\Phi_{H 2}$ & Remarks \\
\hline 1 & 2.5 & 1,605 & 9.66 & 3,086 & 0 & 0 & Sensor test \\
2 & & 1,608 & 9.6 & 3,075 & 0 & 0 & Sensor test \\
3 & & 1,595 & 9.53 & 3,074 & 0.56 & 0.189 & Liquid fuel \\
4 & & 1,619 & 9.51 & 3,091 & 0.55 & 0.149 & Liquid fuel \\
5 & & 1,622 & 8 & 2,578 & 0 & 0 & Sensor test \\
6 & & 1,627 & 8.01 & 2,568 & 0.72 & 0.095 & Supercritical fuel \\
7 & & 1,701 & 8.11 & 2,580 & 0.59 & 0 & Supercritical fuel \\
8 & 2 & 1,289 & 4.16 & 2,574 & 0.69 & 0.094 & Supercritical fuel \\
9 & & 1,308 & 4.15 & 2,579 & 0.88 & 0.098 & Supercritical fuel \\
10 & & 1,308 & 4.15 & 2,577 & 0.52 & 0.095 & Supercritical fuel \\
11 & & 1,314 & 3.76 & 2,008 & 0.71 & 0.096 & Supercritical fuel \\
12 & & 1,306 & 4.94 & 3,061 & 0.7 & 0.091 & Supercritical fuel \\
13 & 1,469 & 4.45 & 2,556 & 0.7 & 0.093 & Supercritical fuel \\
14 & 1,686 & 4.75 & 2,539 & 0.7 & 0.093 & Supercritical fuel \\
\hline
\end{tabular}

Mach number Ma. As shown in Fig. 8, after eliminating the data of broken sensors, the averaging processes of pressure and heat flux are taken over the last $50 \%$ time and last $4 \mathrm{~s}$ of each steady stage, respectively. Mach number was estimated using a quasi-onedimensional flow analysis method from the measured pressure (Zhang et al. 2016).

The 14 tests in Table 1 were divided into five groups in Table 2 to study the influence of each parameter. Those tests depending on more than one parameter were not used.

\section{Initial Test of Heat Flux Sensors}

The reliability of the sensors was validated through randomly swapping five pairs of the heat flux sensors under the same experimental conditions. The good agreements indicate that the sensors work fine and are reliable.

Defining the response time as the period of the signal rising from $5 \%$ to $95 \%$, the average response time of heat flux sensors was $8.23 \pm 1.20 \mathrm{~s}$, as shown in Fig. 8(b). Therefore, the test time was doubled to ensure a steady signal output.

\section{Results and Discussion}

\section{Influence of Combustion}

Fig. 9 shows that the static pressure rose significantly due to combustion. The peak pressure was about five times higher than that without combustion. The estimated Mach number indicates that 

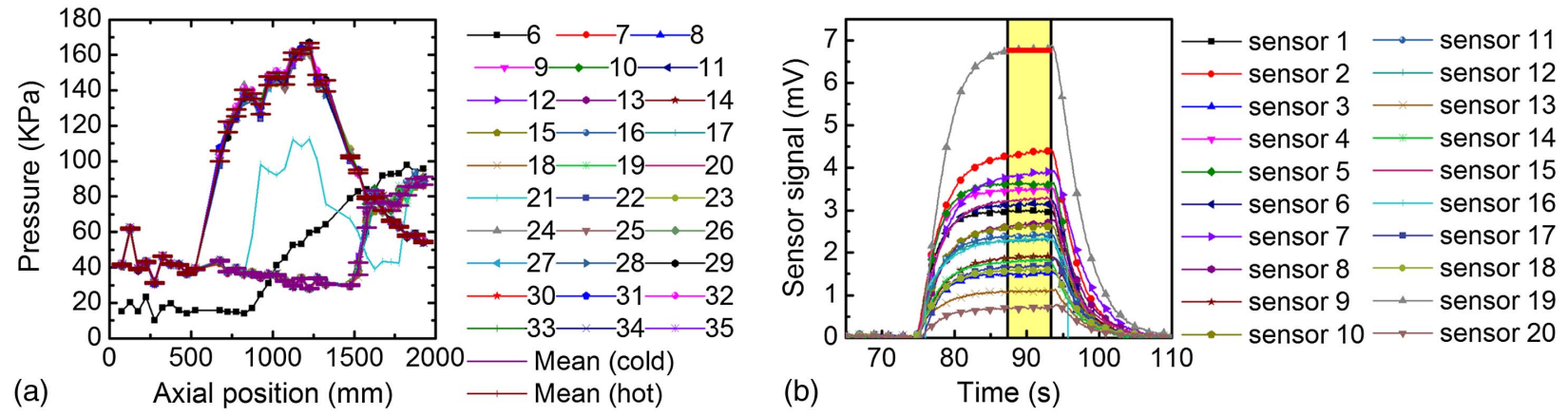

Fig. 8. Averaging of (a) pressure profiles; and (b) heat flux signal.

Table 2. Grouping of the test cases

\begin{tabular}{lccc}
\hline Group number & Test number & Variable & Values \\
\hline 0 & 1,2 & - & Sensor test \\
1 & $10,8,9$ & $\Phi_{k}$ & $0.52,0.69,0.88$ \\
2 & 6,14 & $M a$ & $2.5,2.0$ \\
3 & $11,8,12$ & $q_{m}(\mathrm{~g} / \mathrm{s})$ & $2,008,2,574,3,061$ \\
4 & $8,13,14$ & $T_{0}(\mathrm{~K})$ & $1,289,1,469,1,686$ \\
\hline
\end{tabular}

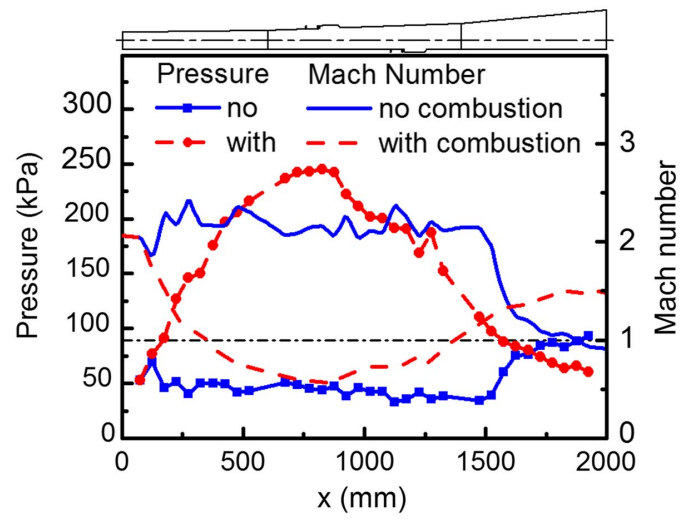

Fig. 9. Pressure on the front wall and Mach number with or without combustion.

the combustor was operating in ramjet mode. The peak of static pressure occurred at the leading edge of the upstream cavity, which is before that of heat flux. The observation of no obvious pressure rise at the outlet indicates that the back pressure-induced flow separation was suppressed in the test with combustion because the flow was accelerated to a higher Mach number at the outlet of the expander section.

Fig. 10 shows that the heat flux overall had a significant rise due to combustion. As observed, the peak heat flux was around five times as high as that without combustion. As shown in Fig. 9, the flow was significantly decelerated to even subsonic by the intense heat addition; therefore, both the aerodynamic heating and the heat released by combustion reactions contribute to the rise of the wall heat flux. Under the combustion condition, heat flux on the upper wall rose relatively smoothly from the inlet of the isolator, which indicates that an observable boundary layer thickening or separation was incurred in the isolator. Heat flux on the lower wall had a drastic rise from the upstream cavity due to the intense heat release from the combustion. The streamwise variations of heat flux under the noncombustion condition were relatively small and all around $25 \mathrm{~W} / \mathrm{cm}^{2}$. The decreasing trend of heat flux on both walls under the noncombustion condition was due to the expansion of the quasi-isentropic flow in the combustor. The heat flux distributions under the combustion condition are asymmetrical on the upper and lower walls due to the two dislocated cavities. At some streamwise locations, the heat flux on different walls could vary by a factor of two, which indicates that the flow was thermally stratified in the burner and expander sections, at least locally. The jet penetration depth estimated from the jet-to-crossflow momentum flux ratio (Billig and Schetz 1966) was approximately $10 \times D_{k} \approx 10 \mathrm{~mm}$ ( $D_{k}=$ injector diameter for kerosene) in the tests while the height of combustor was larger than $70 \mathrm{~mm}$; it is not surprising that the combustion was confined to the fuel injection side and the reacted products on one side could not penetrate to the opposite wall. The heat flux at the third measuring point on the lower wall had a drastic drop compared with its neighbors, either for the combustion or noncombustion case. This is because of the impingement of the cold
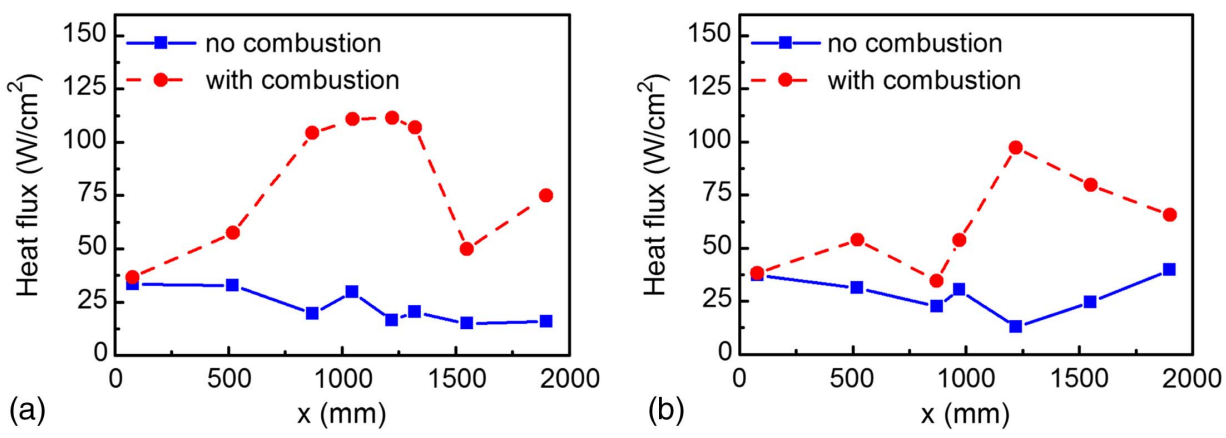

Fig. 10. Heat flux with or without combustion on (a) upper; and (b) lower walls. 


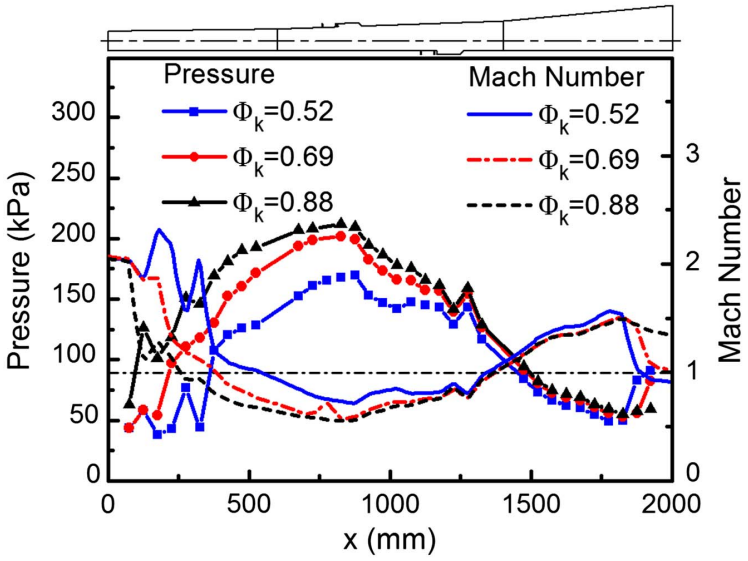

Fig. 11. Pressure on the front wall and Mach number under $\Phi_{k}=0.52$, 0.69 , and 0.88 .

fuel jet wake to the opposite side wall at a slightly downstream location. The incompletely reacted fuel from the upstream as well as the downstream fuel continued to react near the downstream cavity, where the peak of the heat flux on the lower wall resided. The outward expanding of the upper wall with respect to the burner section also contributed to the steep decline of heat flux on the upper wall in the expander section because it aggravated the thermal stratification. The wall temperature can be considered independent of the internal combustion because the water temperature in the water cooling system rose in a limited way. The most influential factor for the wall heat flux was possibly the thermal stratification phenomenon, which has been observed in many previous studies (Yao et al. 2016, 2018b). For supersonic combustors with dislocated cavities, thermal stratification is more severe and can even lead to a local ablation. The heat flux rose again at $x=1,900 \mathrm{~mm}$ on the upper wall, the underlying cause of which is unknown; thus, optical flow diagnostics or high-fidelity modeling should be resorted to. Compared to the noncombustion case, the flow in the expander section was accelerated to a higher Mach number by the stronger combustion-induced pressure, and the pressure at the outlet was lower. Correspondingly, the flow was easier to separate by the ambient pressure at 1 bar. It was observed that the flow separation at the outlet only occurred near the upper wall, whereas no obvious flow separation occurred near the lower wall. This could be due to the side expansion facilitating the penetration of back pressure.

\section{Influence of Global Equivalence Ratio}

In test Group 1 in Table 2, the global equivalence ratio of supercritical kerosene $\Phi_{k}$ increased from 0.52 and 0.69 to 0.88 . The fuel injection Mach number was 1 because the flow was choked immediately before injection. The value of $\Phi_{k}$ was changed through adjusting the total pressure in the upstream fuel tank. As shown in Fig. 11, the combustion-induced pressure rise in the isolator moved upstream and the peak pressure increased with $\Phi_{k}$. The estimated Mach number indicates that the starting point of the subsonic region moved upstream, whereas the ending point stayed fixed as $\Phi_{k}$ increased. The combustors all ran in ramjet mode under the current examined equivalence ratios from 0.52 to 0.88 .

Fig. 12 shows the heat flux profiles when the global kerosene equivalence ratio $\Phi_{k}$ varies from $0.52,0.69$, and 0.88 under the combustion condition. In the examined range of global equivalence ratios, the changes in heat flux were mostly smaller than $15 \%$, and the increments of local heat flux seem to be nonmonotonous with the increase of $\Phi_{k}$. One interesting phenomenon is the abrupt rise of the heat flux rise at the equivalence ratio of 0.88 for the first measuring point on the lower wall, which can be attributed to the combustion-induced pressure rise propagated upward to the isolator inlet. It is evidence of the shock wave-induced heat flux rise in the isolator. Contrary to common sense, the peak heat flux at the upstream cavity decreased slightly with the increase of the global equivalence ratio. There was a secondary peak in heat flux distributions near the downstream cavity, which is in accordance with the static pressure profiles for dual-cavity combustors (Yao et al. 2018b). The values of the secondary peaks increased with the equivalence ratio, probably because the fuel was completely reacted and most of the heat of combustion was released to there. Similarly, separation-induced heat flux rises were only observed on the upper wall.

As in Fig. 13, the total thermal load, which is the surface integration of wall heat flux imposed by the hot combustion gas to all the walls of the burner section, can be estimated by the outlet temperature of the cooling water at a fixed mass flow rate of $2.23 \pm 0.01 \mathrm{~kg} / \mathrm{s}$. The curve of the time-dependent outlet temperature during the tests indicated that the thermal load maintained roughly the same level. The variation in the water temperature was generally small, given that (1) the dependence of heat flux on $\Phi_{k}$ was weak; (2) the mass flow rate of the cooling water was rather high; and (3) the liquid water had a relatively high heat capacity. The peak values even slightly decreased with the increase of the global equivalence ratio. A possible explanation for the inverse dependence of the total thermal load on the global equivalence ratio can be related to the jet penetration depth. In the tests, the way to vary the global equivalence ratio was to adjust the stagnation pressure of the fuel stream. Corresponding to the global equivalence ratios of 0.88 , 0.69 , and 0.52 , the upstream pressure of the supercritical kerosene decreased from $49 \times 10^{5} \mathrm{~Pa}$ (49 bar), $37.9 \times 10^{5} \mathrm{~Pa}$ (37.9 bar) to $28.7 \times 10^{5} \mathrm{~Pa}$ (28.7 bar). Thus, under a lower equivalence ratio, the penetration depth reduced accordingly. As the hot combustion layer approached to the wall, more heat was transferred to the wall,
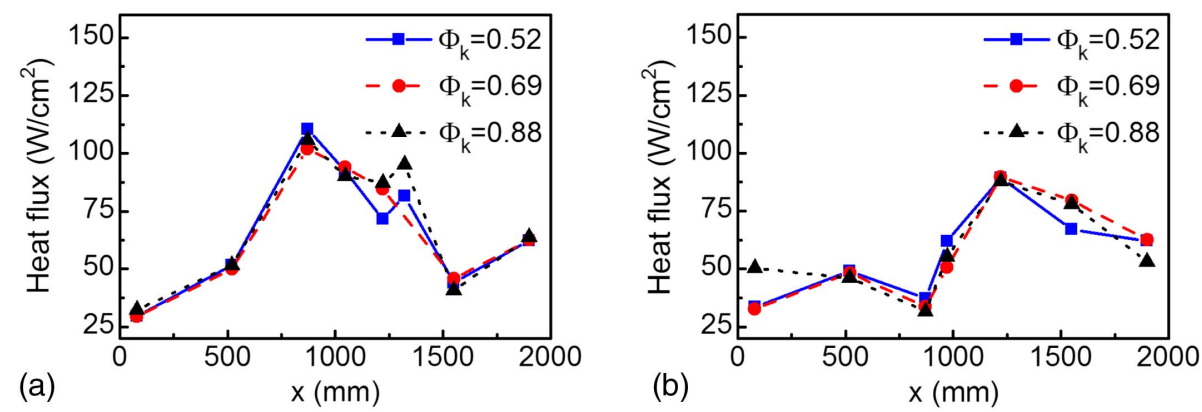

Fig. 12. Heat flux under $\Phi_{k}=0.52,0.69$, and 0.88 on (a) upper; and (b) lower walls, keeping $T_{0}=1,300 \mathrm{~K}$ and $\dot{m}_{\text {air }}=2.5 \mathrm{~kg} / \mathrm{s}$. 


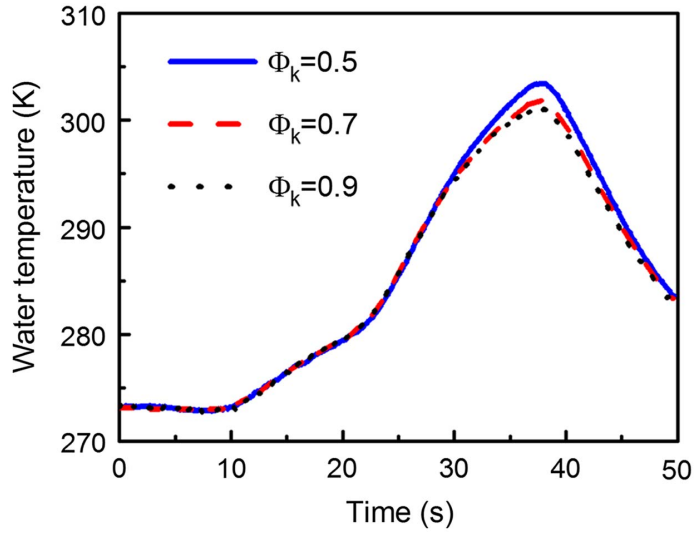

Fig. 13. Time-variant cooling water temperature.

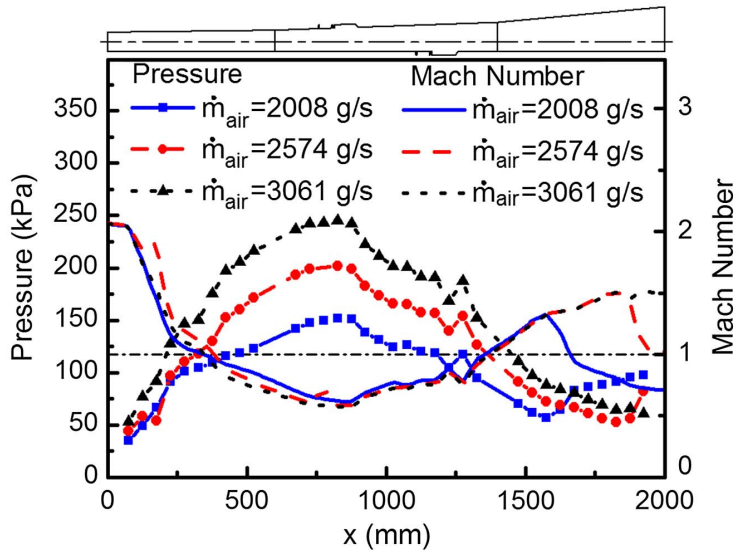

Fig. 14. Pressure on the front wall and Mach number under $\dot{m}_{\text {air }}=2,008,2,574$, and $3,061 \mathrm{~g} / \mathrm{s}$.

although the total heat release decreased. As seen, there was a counterbalance effect induced by the variations in the jet penetration depth and the heat released under different global equivalence ratios; that is, the contributions of increasing the heat release and increasing the jet penetration depth may have counterbalanced each other, which also explains the weak dependence of the heat flux on $\Phi_{k}$ in Fig. 11. However, a flow field reproduced by numerical modeling may be needed to verify this explanation. As the fuel equivalence ratio increases, the cold fuel jet wake gets closer to the opposite wall; thus, the heat flux at the third measuring point decreases further.

\section{Influence of Mass Flow Rate}

The results of test Group 2 are shown in Fig. 14, where the overall pressure increased almost monotonously with the increase of mass flow rate except at the separation zone near the outlet. The estimated Mach number varied modestly as the mass flow rate increased. This is possible because the sonic and flow speed increased simultaneously as both the gas temperature and pressure were raised by the heat addition. However, the resistance to flow separation near the outlet strengthened, as indicated by the higher exit Mach number and the smaller pressure rise when at a higher mass flow rate.

Different mass flow rates of the vitiated air $\left(\dot{m}_{\text {air }}\right)$ crossflow, 2,008, 2,574 and 3,061 g/s, were tested, as shown in Fig. 15. On both the upper and lower walls, the heat flux generally increased with the increase of the mass flow rate. From the Reynolds analogy, the convective heat transfer can be estimated by the refined reference enthalpy method (Meador and Smart 2005)

$$
\dot{q}_{w}=\mathrm{St}^{*} \cdot \rho^{*} V_{e} \cdot C_{p} \Delta T=\frac{0.0287}{P_{r}^{2 / 5} \operatorname{Re}_{x}^{1 / 5}} \frac{\dot{m}_{\mathrm{air}}}{A} C_{p} \Delta T \sim \dot{m}_{\mathrm{air}}^{0.8}
$$

where $\mathrm{St}^{*}=$ reference Stanton number; $\rho^{*}=$ reference density; $V_{e}=$ velocity of the gas in the adjacent inviscid flow at the outer edge of the boundary layer; $C_{p}=$ specific heat; $\Delta T=$ temperature difference between an adiabatic wall and the real wall; $A=$ flow-through area; $P_{r}=$ turbulent Prandtl number; and $\operatorname{Re}_{x}=$ local Reynolds number. The previous relation explains the observation that the heat flux varies nearly proportionally with the mass flow rate. The reference enthalpy method was developed for both laminar and turbulent compressible boundary layers. The previous equation was developed for both laminar and turbulent compressible boundary layers and is valid only for nonreacting flows, for example, the flow in the isolator section. As the mass flow rate of the crossflow increases, the total heat release increases under the same global equivalence ratio of 0.7 ; thus, the heat flux on both the upper and lower walls in the burner section has more pronounced rises for a higher mass flow rate. At a lower mass flow rate, the flow at the exit is more prone to be separated because the crossflow momentum has become weaker to counterbalance the adverse pressure gradient imposed by the ambient environment. Thus, the last heat flux measurement at $x=1,900 \mathrm{~mm}$ on the upper wall at the mass flow rate of $2,008 \mathrm{~g} / \mathrm{s}$ rises mildly and exceeds that at $2,574 \mathrm{~g} / \mathrm{s}$.

\section{Influence of Total Temperature}

For the same mass flow rate, the rise in $T_{0}$ increased the flow speed of the crossflow. The total pressure was adjusted to maintain the same inlet Mach number. The test results of Group 3, as shown
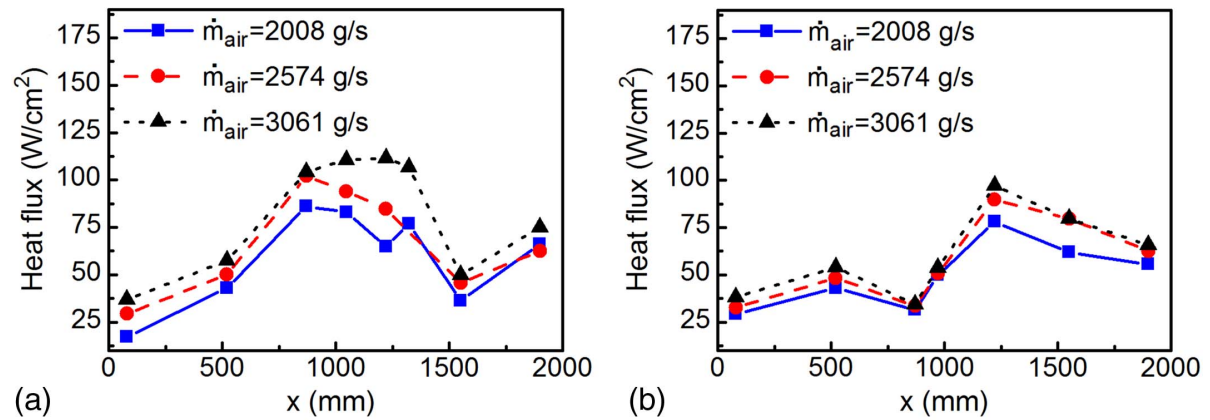

Fig. 15. Heat flux under $\dot{m}_{\text {air }}=2,008,2,574$, and 3,061 g/s on (a) upper; and (b) lower walls, keeping $T_{0}=1,300 \mathrm{~K}$ and $\Phi_{k}=0.7$. 
in Fig. 16, indicate that the increase of $T_{0}$ moved the location of the initial pressure rise in the isolator downstream and slightly decreased the peak pressure, but the pressure after the peak changed weakly. Due to the increase in the flow entry speed, the shock train in the isolator slid farther downstream, and the Mach number increased in the isolator. The reduction in length of the subsonic region indicates that increasing $T_{0}$ drives the operation mode toward scramjet mode.

Fig. 17 shows that the heat flux increased considerably as the total temperature of the crossflow increased from 1,289 to 1,469 and 1,686 K. On the upper wall, a secondary peak or plateau was formed behind the upstream cavity for the total temperatures of 1,469 and $1,686 \mathrm{~K}$, whereas the heat flux decreased monotonously for the total temperature of $1,289 \mathrm{~K}$. This indicates that the heat release was more concentrated along the streamwise direction. The penultimate measurements at $x=1,550 \mathrm{~mm}$ on the upper wall overlapped with each other for all cases; the reason could be related to the variation of the streamwise distributions of the heat release rate under different total temperatures. As the total temperature increased, the combustion reactions proceeded more toward chemical equilibrium within a shorter distance because the fuel injection, and, correspondingly, the downstream reactivity receded to produce a weaker heat release rate and wall heat flux.

\section{Influence of Inlet Mach Number}

Fig. 18 shows the influence of the inlet Mach number following the tests in Group 4. As the Mach number increased, the location

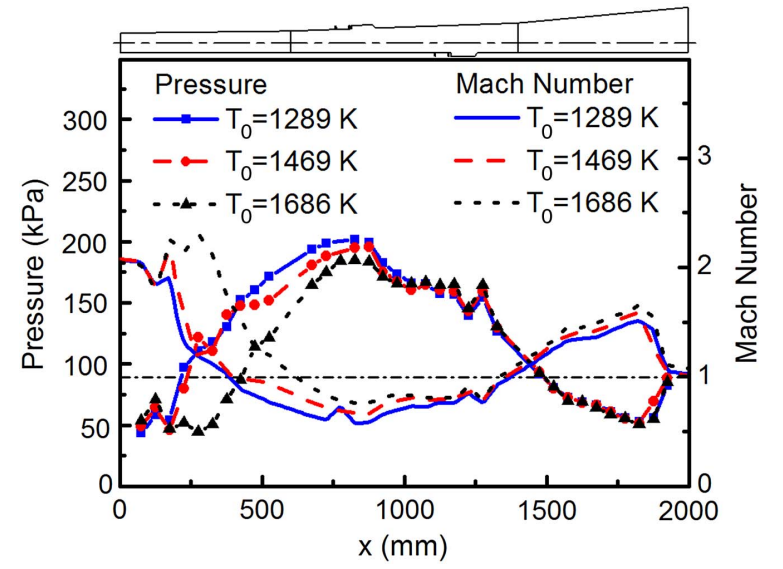

Fig. 16. Pressure on the front wall and Mach number under $T_{0}=1,289,1,469$, and $1,686 \mathrm{~K}$.

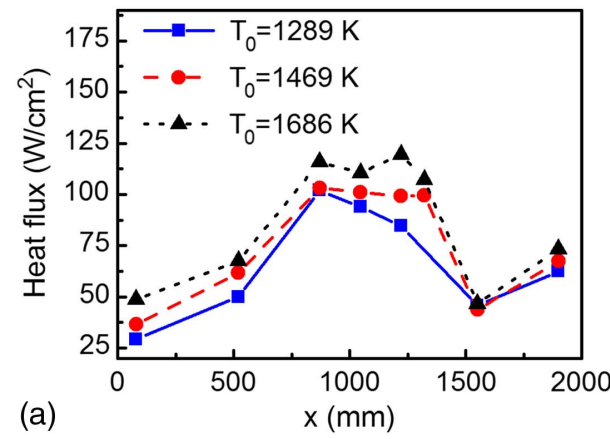

of the initial pressure rise slid downstream, and the overall pressure decreased because the shock train had to move to a farther downstream location to balance the increased speed of the crossflow (Yao et al. 2018b). The pressure in the expander section was less influenced. The estimated Mach number indicates that the subsonic region diminished and the operation mode of the supersonic combustor transited from ramjet to scramjet mode as the Mach number increased.

Fig. 19 shows the heat flux under the inlet Mach numbers of 2.0 and 2.5 while fixing the total temperature. On the upper wall, the heat flux was overall higher for $\mathrm{Ma}=2.0$. On the lower wall, the heat flux at $\mathrm{Ma}=2.0$ was initially higher but then became lower than that at $\mathrm{Ma}=2.5$ behind the upstream fuel injection. Under the fixed total temperature, a higher Mach number implies a higher Reynolds number and lower Stanton number. The recovery temperature was also lower at a higher Mach number. As a result, the heat flux in the isolator was lower for the $\mathrm{Ma}=2.5$ case. A lower Mach number would always facilitate combustion reactions as the flow residence time, static temperature, and jet penetration depth all increase; thus, the heat release increases and, correspondingly, the wall heat flux rises. In the tests, the increase in the heat release and the reduction of inlet Ma from 2.5 to 2.0 together drove the combustion mode from scramjet to ramjet. The incompletely reacted fuel together with the intermediate species convected from the upstream would continue to react near the downstream cavity, and this possibly explains the surpassing of the heat flux on the lower wall at $\mathrm{Ma}=2.5$ relative to that at $\mathrm{Ma}=2.0$.

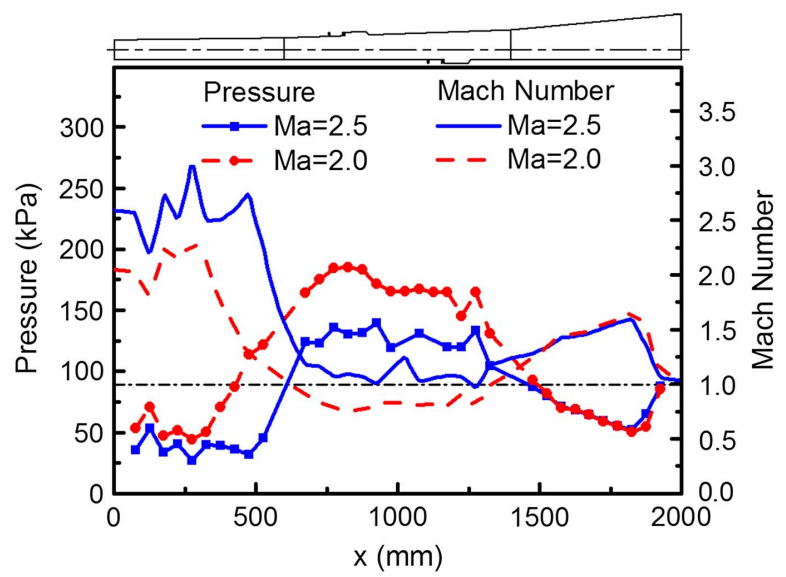

Fig. 18. Pressure on the front wall and Mach number under $\mathrm{Ma}=2.0$ and 2.5 .

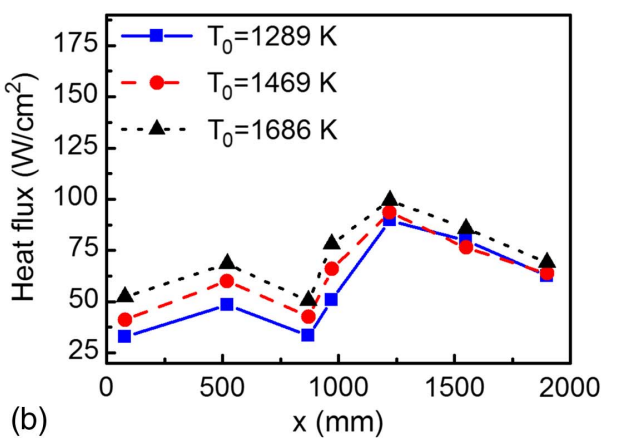

Fig. 17. Heat flux under $T_{0}=1,289,1,469$, and $1,686 \mathrm{~K}$ on (a) upper; and (b) lower walls, keeping $\dot{m}_{\text {air }}=2.5 \mathrm{~kg} / \mathrm{s}$ and $\Phi_{k}=0.7$. 

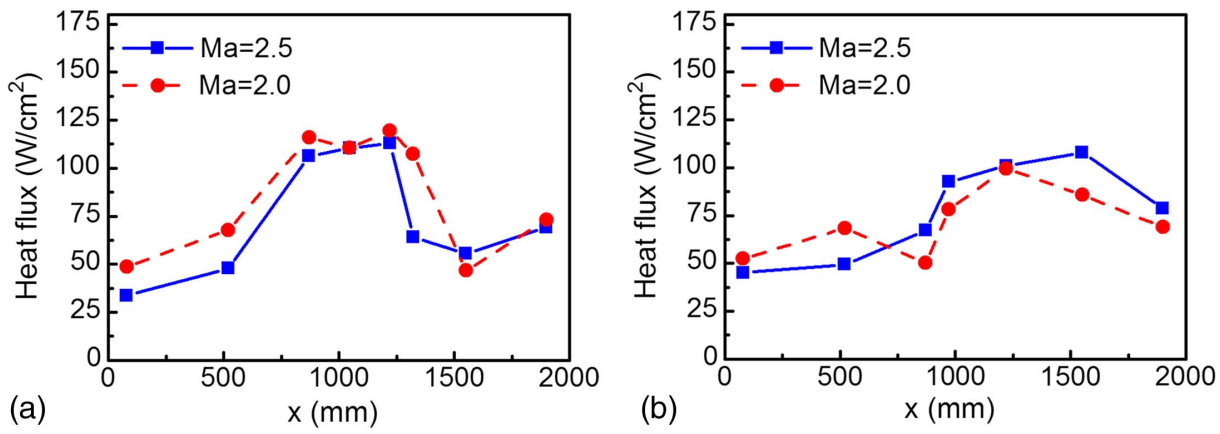

Fig. 19. Heat flux under $\mathrm{Ma}=2.0$ and 2.5 on (a) upper; and (b) lower walls, keeping $T_{0}=1,650 \mathrm{~K}, \dot{m}_{\text {air }}=2.5 \mathrm{~kg} / \mathrm{s}$, and $\Phi_{k}=0.7$.

\section{Conclusion}

In this study, measurements of pressure and heat flux distributions of a water-cooled supersonic combustor under different parameter configurations were conducted. The peak pressure was about five times higher than that without combustion. Back pressure-induced flow separation was observed to be suppressed in the combustion case. The heat flux under combustion had a significant rise compared with the noncombustion case, and a clear thermal stratification can be expected from the substantial difference between the upper and lower heat flux. With the increasing of global equivalence ratio, the initial pressure rise moved farther upstream, and the peak pressure increased. However, the influence of the global equivalence ratio on the heat flux distribution was observed to be small and nonmonotonous, which is possibly related to the aliasing effect brought about by the variations in the jet penetration depth and the heat release under different global equivalence ratios. The overall pressure increased monotonously with the increase of the mass flow rate except at the separation zone near the outlet. The heat flux varied with the mass flow rate of vitiated air as $\dot{q}_{w} \sim \dot{m}_{\text {air }}^{0.8}$. The increase of total temperature moved the location of initial pressure rise in the isolator downstream and slightly decreased the peak pressure, but the pressure after the peak changed little. The heat flux increased considerably with the increase of total temperature as the combustion reactions proceeded more toward chemical equilibrium and the observed heat flux was more concentrated along the streamwise direction. As the Mach number increased, the location of the initial pressure rise slid downstream and the overall pressure decreased. The influence of the inlet Mach number is more complicated, but generally a lower Mach number would always facilitate the combustion reactions as the flow residence time, flow temperature, and jet penetration depth all increase; thus, the heat release together with the wall heat flux increases. A quasi-one-dimensional correlation for noncombustion and nonseparation sections is proposed to relate the wall heat flux to the total temperature, mass flow rate of vitiated air, and inlet Mach number.

\section{Appendix. Quasi-One-Dimensional Correlation for Noncombustion and Nonseparation Sections}

The heat flux can be calculated from the inner wall temperature $\left(T_{w}\right)$ and the recovery temperature $\left(T_{a w}\right)$ as

$$
\dot{q}_{w}=h\left(T_{a w}-T_{w}\right)
$$

where $h=$ convective heat transfer coefficient. The value of $T_{a w}$ can be estimated from the reference enthalpy method (Meador and Smart 2005) as

$$
\mathrm{T}_{a w}=T_{e}+\sqrt[3]{P_{r}^{*}} \frac{V_{e}^{2}}{2 C_{p}}=T_{0} \frac{1+\sqrt[3]{P_{r}^{*}} \cdot \frac{\gamma-1}{2} \mathrm{Ma}^{2}}{1+\frac{\gamma-1}{2} \mathrm{Ma}^{2}}=T_{0} f\left(\mathrm{Ma}^{2}\right)
$$

where $T_{e}=$ temperature of the gas in the adjacent inviscid flow at the outer edge of the boundary layer; $P_{r}^{*}=$ reference Prandtl number; and $\gamma=$ ratio of specific heats. The function $f\left(\mathrm{Ma}^{2}\right)$ is an asymptotic function that decreases approximately linearly for $1<\mathrm{Ma}^{2} \leq 5$ and approaches a constant value as Ma increases further. Substituting the typical values of $P_{r}^{*} \approx 0.73$ and $\gamma \approx$ 1.30 yields $f\left(\mathrm{Ma}^{2}\right)=0.95 \pm 0.01$ for $2<\mathrm{Ma} \leq 3$. This shows that $T_{a w}$ is primarily determined by $T_{0}$ and has a weak dependence on the Mach number in the typical range of inlet Mach numbers.

With the recirculating cooling water and the thermal resistant coating, $T_{w}$ increases slightly as the wall heat flux increases. It can be assumed that the dependence of $T_{w}$ on the inlet Ma follows the same function of $f\left(\mathrm{Ma}^{2}\right)$; that is, $T_{w}=T_{w 0} f\left(\mathrm{Ma}^{2}\right)$ with a constant $T_{w 0}$. Then, the variation of wall heat flux depends on the changes of $h, T_{0}$, and $\mathrm{Ma}$ as

$$
\dot{q}_{w} \sim h \cdot\left(T_{0}-T_{w 0}\right) \cdot f\left(\mathrm{Ma}^{2}\right)
$$

Variation in the gas temperature usually changes both $T_{0}$ and $h$. Thus, the contributions of $T_{0}$ and $h$ to the ensemble heat flux are sometimes difficult to isolate. Moreover, the heat flux distribution is synthetically influenced by various flow parameters; thus, a nonmonotonous variation may appear.

For a turbulent flat-plate boundary layer, $h$ is estimated by the Reynolds analogy (Heiser and Pratt 1994) as

$$
\begin{aligned}
h=\mathrm{St}^{*} \cdot \rho^{*} V_{e} \cdot C_{p} & =\frac{0.0287}{P_{r}^{2 / 5} \operatorname{Re}_{x}^{1 / 5} \frac{\dot{m}_{\mathrm{air}}}{A} C_{p}} \\
& =\frac{0.0287 \mu^{0.2} C_{p}}{P_{r}^{2 / 5}} \cdot \dot{m}_{\mathrm{air}}^{0.8} \cdot A^{-0.8} \cdot x^{-0.2}
\end{aligned}
$$

where $\mu=$ viscosity. The previous equation shows that for an undisturbed turbulent boundary layer, $h$ will decrease with the streamwise distance $x$ in an exponential manner $\left(x^{-0.2}\right)$ on a flat plate. Eq. (7) is only valid for nonreacting flows.

From Eqs. (6) and (7), a three-parameter correlation is proposed

$$
\dot{q}_{w} \sim \dot{m}_{\mathrm{air}}^{0.8} \cdot\left(T_{0}-T_{w 0}\right) \cdot\left(1+b \cdot \mathrm{Ma}^{2}\right)
$$

where the dependence of the Mach number $f\left(\mathrm{Ma}^{2}\right)$ is simply represented by the first-order polynomial with a constant $b$. The boundary layer in a supersonic combustor may be thickened or even separated by an adverse pressure gradient caused by shock waves, mechanical blockage, and combustion (Nithish Reddy and Venkatasubbaiah 2015). Even small local separation can cause a 
Table 3. Parameter configurations and average heat flux

\begin{tabular}{ccccc}
\hline $\mathrm{Ma}$ & $T_{0}(\mathrm{~K})$ & $\dot{m}_{\text {air }}(\mathrm{kg} / \mathrm{s})$ & $\overline{\dot{q}}_{w}\left(\mathrm{~W} / \mathrm{cm}^{2}\right)$ & Fitted value $\left(\mathrm{W} / \mathrm{cm}^{2}\right)$ \\
\hline 2.5 & 1,605 & 3.086 & 39.59 & 40.56 \\
& 1,608 & 3.075 & 40.22 & 40.57 \\
& 1,595 & 3.074 & 38.78 & 39.99 \\
& 1,619 & 3.091 & 40.74 & 41.18 \\
& 1,622 & 2.578 & 36.91 & 35.72 \\
& 1,627 & 2.568 & 37.47 & 35.81 \\
& 1,701 & 2.58 & 39.15 & 38.68 \\
2 & 1,289 & 2.574 & 28.73 & 28.18 \\
& 1,308 & 2.579 & 29.16 & 29.05 \\
& 1,308 & 2.577 & 29.05 & 29.07 \\
& 1,314 & 2.008 & 23.11 & 24.03 \\
& 1,306 & 3.061 & 33.67 & 33.22 \\
1,469 & 2.556 & 35.58 & 35.94 \\
& 1,686 & 2.539 & 45.29 & 45.25 \\
\hline
\end{tabular}

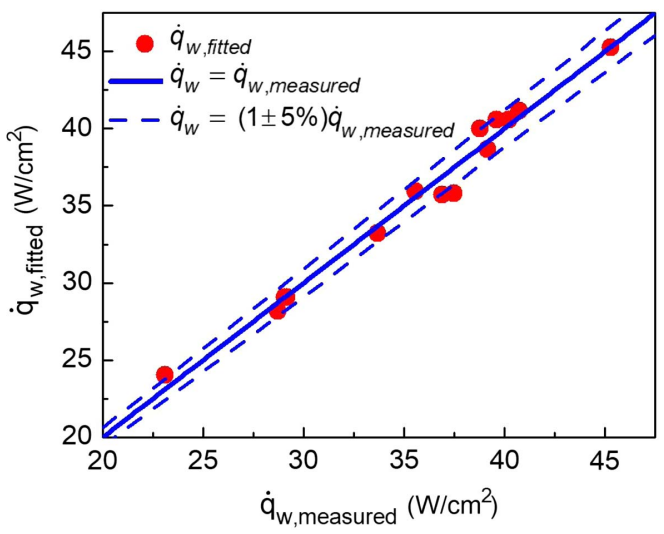

Fig. 20. Data fitting of wall heat flux using Eq. (8).

rise in the heat flux at a factor of 2-3 (Markarian 1968). The heat flux rise at the exit of the combustor caused by pressure-induced flow separation is evidence of the influence of an adverse pressure gradient. Thus, the correlation Eq. (8) is only applicable to noncombustion and nonseparation sections. To avoid the interference of those back pressure-induced three-dimensional effects, the average heat flux on the walls in the isolator section as summarized in Table 3 is used to fit Eq. (8), where $T_{w 0}=650 \mathrm{~K}$. As shown in Fig. 20, a good fit with the coefficient of determination $R^{2}=0.98$ for the experimental data was obtained by using the previous quasione-dimensional correlation.

\section{Acknowledgments}

The research is supported by the Training Program of the Major Research Plan of National Natural Science Foundation of China (Grant No. 91641110), and the State Scholarship Fund of China Scholarship Council (Grant No. 201704980059).

\section{Notation}

The following symbols are used in this paper:

$A=$ flow-through area $\left(\mathrm{m}^{2}\right)$;

$b=$ constant coefficient;

$C_{p}=$ specific heat at constant pressure $(\mathrm{J} / \mathrm{kg} \cdot \mathrm{K})$;

$D=$ diameter of heat flux sensor $(\mathrm{mm})$;
$D_{k}=$ diameter of kerosene injector ( $\left.\mathrm{mm}\right)$;

$E=$ output voltage signal of heat flux sensor $(\mathrm{mV})$;

$h=$ convective heat transfer coefficient $\left(\mathrm{W} / \mathrm{m}^{2} \cdot \mathrm{K}\right)$;

$K_{1}, K_{2}=$ sensitivity of heat flux and temperature difference of heat flux sensor;

$\dot{m}_{\text {air }}=$ mass flow of vitiated air crossflow $(\mathrm{g} / \mathrm{s})$;

$\mathrm{Ma}=$ Mach number;

$P=$ heating power for calibration $(\mathrm{W})$;

$P_{0}=$ total pressure $(\mathrm{Pa})$;

$P_{\text {fuel }}=$ fuel pressure $(\mathrm{Pa})$;

$\operatorname{Pr}=$ Prandtl number;

$\dot{q}=$ heat flux $\left(\mathrm{W} / \mathrm{m}^{2}\right)$;

$\dot{q}_{w}=$ convective wall heat flux $\left(\mathrm{W} / \mathrm{m}^{2}\right)$;

$q_{m}=$ mass flow rate;

$R^{2}=$ coefficient of determination;

$\operatorname{Re}_{x}=$ local Reynolds number depending on axial location $x$;

$\mathrm{St}=$ Stanton number;

$T_{0}=$ total temperature $(\mathrm{K})$;

$T_{a w}=$ recovery wall temperature $(\mathrm{K})$;

$T_{b}=$ body temperature of heat flux sensor $(\mathrm{K})$;

$T_{e}=$ temperature at outer edge of boundary layer $(\mathrm{K})$;

$T_{h}=$ temperature at head of heat flux sensor $(\mathrm{K})$;

$T_{w}=$ wall temperature $(\mathrm{K})$;

$T_{w 0}=$ temperature constant $(\mathrm{K})$;

$V_{e}=$ flow speed at outer edge of boundary layer $(\mathrm{m} / \mathrm{s})$;

$x=$ axial distance from inlet $(\mathrm{mm})$;

$\gamma=$ adiabatic index;

$\Delta T=$ temperature difference between adiabatic wall and real wall (K);

$\varepsilon=$ wall surface roughness $(\mu \mathrm{m})$;

$\mu=$ viscosity $(\mathrm{kg} / \mathrm{m} \cdot \mathrm{s})$;

$\rho=$ density $\left(\mathrm{kg} / \mathrm{m}^{3}\right)$;

$\emptyset=$ diameter $(\mathrm{mm})$;

$\Phi_{H 2}=$ global equivalence ratio of pilot $\mathrm{H}_{2}$; and

$\Phi_{k}=$ global equivalence ratio of kerosene.

\section{Subscript}

$0=$ stagnation condition; and

$e=$ adjacent inviscid flow at outer edge of boundary layer.

\section{Superscript}

$*=$ reference state in reference enthalpy method.

\section{References}

Billig, F. S., and J. A. Schetz. 1966. "Penetration of gaseous jets injected into a supersonic stream." J. Spacecraft Rockets 3 (11): 1658-1665. https://doi.org/10.2514/3.28721.

Cheng, D., J. Wang, J. Gong, Y. Lu, W. Yao, L. Li, and X. Fan. 2016. "Measurement of heat flux distribution of supercritical kerosene fueled supersonic combustor." In Proc., 32nd AIAA Aerodynamic Measurement Technology and Ground Testing Conf., 4112. Reston, VA: American Institute of Aeronautics and Astronautics.

Gardner, A., J. Steelant, A. Paull, and K. Hannemann. 2004. "Ground testing of the HyShot supersonic combustion flight experiment in HEG and comparison with flight data." In Proc., 40th AIAA/ASME/SAE/ASEE Joint Propulsion Conf. and Exhibit, 3345. Reston, VA: American Institute of Aeronautics and Astronautics.

Heiser, W. H., and D. T. Pratt. 1994. Hypersonic air breathing propulsion. Washington, DC: American Institute of Aeronautics and Astronautics. 
Kennedy, P., J. Donbar, J. Trelewicz, C. Gouldstone, and J. Longtin. 2011. "Heat flux measurements in a scramjet combustor using direct write technology." In Proc., 17th AIAA Int. Space Planes and Hypersonic Systems and Technologies Conf., 2330. Reston, VA: American Institute of Aeronautics and Astronautics.

Li, L., J. Wang, and X. Fan. 2012. "Development of integrated high temperature sensor for simultaneous measurement of wall heat flux and temperature." Rev. Sci. Instrum. 83 (7): 074901. https://doi.org/10 $.1063 / 1.4731685$.

Markarian, C. F. 1968. Heat transfer in shock wave-boundary layer interaction regions. NWC TP 4485. China Lake, CA: Naval Weapons Center.

Meador, W. E., and M. K. Smart. 2005. "Reference enthalpy method developed from solutions of the boundary-layer equations." AIAA $J$. 43 (1): 135-139. https://doi.org/10.2514/1.2656.

Morgan, R. G., and R. J. Stalker. 1986. "Shock tunnel measurements of heat transfer in a model scramjet." J. Spacecraft Rockets 23 (5): 470-475. https://doi.org/10.2514/3.25831.

Nithish Reddy, P., and K. Venkatasubbaiah. 2015. "Numerical investigations on development of scramjet combustor." J. Aerosp. Eng. 28 (5): 04014120. https://doi.org/10.1061/(ASCE)AS.1943-5525.0000456.

Stouffer, S. D., R. D. Neumann, and D. S. Emmer. 1997. Thermal performance of a scramjet combustor operating at Mach 5.6 flight conditions. WL-TR-97-2086. Dayton, OH: Univ. of Dayton Research Institute.

Traci, R. M., J. L. Farr, Jr., T. Laganelli, and J. Walker. 2002. A thermal management systems model for the NASA GTX RBCC concept.
NASA/CR-2002-211587. Torrance, CA: Science Applications International Corporation.

Trelewicz, J. R., J. P. Longtin, C. Gouldstone, P. J. Kennedy, and J. M. Donbar. 2015. "Heat flux measurements in a scramjet combustor using embedded direct-write sensors." J. Propul. Power 31 (4): 1003-1013. https://doi.org/10.2514/1.B35585.

Ueda, S., M. Takegoshi, T. Kouchi, F. Ono, T. Saito, and M. Izumikawa. 2006. "Evaluation of heat-flux on scramjet engine wall in Mach 6 flight condition." In Proc., 57th Int. Astronautical Congress. Paris: International Astronautical Federation.

Yao, W., Y. Lu, X. Li, J. Wang, and X. Fan. 2016. "Improved delayed detached eddy simulation of a high-Ma active-cooled scramjet combustor based on skeletal kerosene mechanism." In Proc., 52nd AIAA/SAE/ ASEE Joint Propulsion Conf., 4761. Reston, VA: American Institute of Aeronautics and Astronautics.

Yao, W., Y. Lu, K. Wu, J. Wang, and X. Fan. 2018a. "Modeling analysis of an actively-cooled scramjet combustor under different kerosene/air ratios." J. Propul. Power 34 (4): 975-991. https://doi.org/10.2514/1 .B36866.

Yao, W., Y. Yuan, X. Li, J. Wang, K. Wu, and X. Fan. 2018b. "Comparative study of elliptic and round scramjet combustors fueled by RP-3." J. Propul. Power 34 (3): 772-786. https://doi.org/10.2514/1.B36721.

Zhang, D., Y. Feng, S. Zhang, J. Qin, K. Cheng, W. Bao, and D. Yu. 2016. "Quasi-one-dimensional model of scramjet combustor coupled with regenerative cooling." J. Propul. Power 32 (3): 687-697. https://doi .org/10.2514/1.B35887. 